\title{
Studies of variability in the PTEN gene among Danish caucasian patients with Type II diabetes mellitus
}

\author{
L.Hansen ${ }^{1}$, J. N. Jensen ${ }^{1}$, C. T. Ekstrøm ${ }^{1}$, H. Vestergaard ${ }^{2}$, T.Hansen ${ }^{1}$, O. Pedersen ${ }^{1}$ \\ ${ }^{1}$ Steno Diabetes Center and Hagedorn Research Institute, Copenhagen, Denmark \\ ${ }^{2}$ Department of Internal Medicine and Endocrinology, University Hospital of Herlev, Copenhagen, Denmark
}

\section{Abstract}

Aim/hypothesis. Phosphatase and tensin homologue deleted from chromosome ten (PTEN) has recently been characterized as a novel member in the expanding network of proteins regulating the intracellular effects of insulin. By dephosphorylation of phosphatidyl-inositol- $(3,4,5)$-trisphosphate $\left(\mathrm{PIP}_{3}\right)$ the PTEN protein regulates the insulin-dependent phosphoinositide 3-kinase $\left(\mathrm{PI}_{3} \mathrm{~K}\right)$ signalling cassette and accordingly might function as a regulator of insulin sensitivity in skeletal muscle and adipose tissue. In this study we tested PTEN as a candidate gene for insulin resistance and late-onset Type II (non-insulin-dependent) diabetes mellitus in a Danish Caucasian population. Methods. The nine exons of the PTEN, including intronic flanking regions were analysed by PCR-SSCP and heteroduplex analysis in 62 patients with insulinresistant Type II diabetes.

Results. No mutations predicted to influence the expression or biological function of the PTEN protein but four intronic polymorphisms were identified:
IVS1-96 $\mathrm{A} \rightarrow \mathrm{G}$ (allelic frequency 0.22, 95\% CI: $0.12-0.32), \quad$ IVS3 $+99 \quad \mathrm{C} \rightarrow \mathrm{T} \quad(0.01, \quad \mathrm{CI}: \quad 0-0.03)$, IVS7-3 TT $\rightarrow$ T $(0.10, \mathrm{CI}: 0.03-0.18)$ and IVS $8+32$ $\mathrm{G} \rightarrow \mathrm{T}(0.35$, CI: $0.23-0.47)$. The IVS $8+32 \mathrm{G} \rightarrow \mathrm{T}$ polymorphism was used as a bi-allelic marker for the PTEN locus and examined in 379 patients with Type II diabetes and in 224 control subjects with normal glucose tolerance. The IVS $8+32 \mathrm{G} \rightarrow \mathrm{T}$ polymorphism in the PTEN was not associated with Type II diabetes and it did not have any effect on body-mass index, blood pressure, HOMA insulin resistance index, or concentrations of plasma glucose, serum insulin or serum $\mathrm{C}$ peptide obtained during an oral glucose tolerance test (OGTT).

Conlusion/interpretation. Variability in the PTEN is not a common cause of Type II diabetes in the Danish Caucasian population. [Diabetologia (2001) 44: 237240]

Keywords PTEN, mutation, Type II diabetes mellitus, SSCP, RFLP.
Impaired insulin-stimulated glycogen synthesis of skeletal muscle is among the most consistent patho-

Received: 31 July 2000 and in revised form: 20 August 2000

Corresponding author: Lars Hansen, MD, Steno Diabetes Center, Niels Steensens Vej 2, DK-2820 Gentofte, Copenhagen, Denmark

Abbreviations: PTEN, Phosphatase and tensin homlogue deleted from chromosome ten; $\mathrm{PIP}_{3}$, phosphatidyl-inositol-(3, 4, 5)-triphosphate; $\mathrm{PI}_{3} \mathrm{~K}$, phosphoinositide 3-Kinase; IVS, intronic variant sequence; PKB, protein kinase B; SSCP, single stranded conformation polymorphism; HOMA, homeostasis model of assessment. physiological characteristics of late-onset Type II diabetes and studies of glucose-tolerant first degree relatives of patients with late-onset Type II diabetes have shown that decreased insulin sensitivity in the whole body and impaired insulin-stimulated glycogen synthesis of skeletal muscle precede the onset of Type II diabetes [1]. The genetic basis of these findings, however, is mostly not known but genes encoding proteins, active in the continuously expanding network of interacting molecules constituting the insulin signalling pathways, are plausible candidates for insulin resistance and Type II diabetes [2]. Metabolic effects of insulin (glucose uptake and glycogen synthesis) 
Table 1. Clinical and physiological characteristics of the 62 Type II diabetic patients that were included in the primary study of variability in the PTEN compared with 20 normal glucose-tolerant control subjects.

\begin{tabular}{|c|c|c|c|}
\hline & Patients & Control subjects & $p$-value \\
\hline No. & 62 & 20 & - \\
\hline Age (years) & $52(8)$ & 49 (17) & NS \\
\hline BMI $\left(\mathrm{kg} / \mathrm{m}^{2}\right)$ & $29(8)$ & $28(8)$ & NS \\
\hline f-p-glucose $(\mathrm{mmol} / \mathrm{l})$ & $10.9(4.1)$ & $5.5(0.8)$ & $<0.0001$ \\
\hline $\mathrm{f}$-s-insulin $(\mathrm{pmol} / \mathrm{l})$ & $81(50)$ & $64(50)$ & NS \\
\hline f-s-C peptide $(\mathrm{pmol} / \mathrm{l})$ & $730(332)$ & $710(332)$ & NS \\
\hline Steady-state serum insulin during clamp ${ }^{c}$ & $1102(266)$ & $1051(457)$ & NS \\
\hline
\end{tabular}

Data represent means $(\mathrm{SD}) . \mathrm{f}=$ fasting; $\mathrm{s}=$ serum; $\mathrm{p}=$ plasma; $\mathrm{NS}=$ non significant

a indicates basal whole body glucose disposal ( $\mathrm{mol} / \mathrm{l})$ value

$\mathrm{b}$ indicates clamp value of insulin-stimulated whole body glucose disposal $\left(\mathrm{M}_{\text {clamp }}\right)$

are most likely mediated through the $I R / I R S / P I_{3} \mathrm{~K}$ signalling cassette and, hypothetically, abnormalities caused by genetic variabilities in these proteins might impair signalling and present as decreased insulinstimulated glucose uptake and glycogen synthesis [2].

Recently, the protein phosphatase PTEN (also known as MMAC or TEP1) [3] has been introduced into the insulin signalling cassette as a lipid phosphatase that negatively regulates the concentration of intracellular phosphatidyl-inositol- $(3,4,5)$-trisphosphate generated in response to the activation of phosphoinositide 3-kinase $\left(\mathrm{PI}_{3} \mathrm{~K}\right)$ [4], preventing the downstream phosphatidylinositol $(3,4,5)$-trisphosphate $\left(\mathrm{PIP}_{3}\right)$-dependent activation of protein kinase $\mathrm{B}$ (PKB). Activation of the $\mathrm{PI}_{3} \mathrm{~K}$ and $\mathrm{PKB}$ is an essential step in the insulin-stimulated glucose uptake and glycogen synthesis [2], and recent studies of the regulation of $\mathrm{PI}_{3} \mathrm{~K}$ and $\mathrm{PKB}$ isoforms in insulin-sensitive liver, muscle and adipose tissues in the obese Zucker rat model of insulin resistance suggest that PTEN is a potential candidate for regulating the signal transduction between $\mathrm{PI}_{3} \mathrm{~K}$ and $\mathrm{PKB}$ [5]. This has been further investigated in the $\mathrm{db} / \mathrm{db}$ insulin-resistant mice where inhibition of PTEN expression by the use of antisense technology improves insulin resistance and reverses hyperglycaemia [6]. As a modulator of insulin sensitivity, we considered PTEN a potential candidate gene for the development of insulin resistance and Type II diabetes. To test this hypothesis we carried out a mutational analysis of coding regions including exon and intron boundaries of the PTEN in 62 patients with Type II diabetes.

\section{Materials and methods}

Subjects. All patients with Type II diabetes were recruited at the outpatient clinic at Steno Diabetes Center, Copenhagen, and glucose-tolerant control subjects were traced through the
${ }^{c}$ indicates steady-state serum insulin concentration during the euglycemic hyperinsulinaemic 4 h clamp (7)
Danish Central Personal Register. Type II diabetes was diagnosed according to the 1985 World Health Organisation (WHO) criteria and all the patients tested negative for antiGAD antibodies. Before participation, the purpose and risk of the study were explained, and informed consent was obtained from all the participants. The protocol was approved by the ethics committee of Copenhagen and was in accordance with the Helsinki declaration II.

For primary mutation analysis DNA was isolated from leukocytes [8] of 62 patients with Type II diabetes (Table 1) and association studies were done in 379 unrelated patients with Type II diabetes (age, $61 \pm 11$ years; BMI, $29 \pm 5 \mathrm{~kg} / \mathrm{m}^{2}$; age of clinical onset of diabetes, $55 \pm 5$ years). Of the patients $28 \%$ were diet treated, $58 \%$ were treated with sulphonylurea or biguanide or both, and $14 \%$ were treated with insulin. The characteristics of 224 matched unrelated glucose-tolerant control subjects are shown (Table 2).

Genetic analyses. Mutation analysis of the PTEN was done by polymerase-chain-reaction single-stranded-conformationpolymorphism (PCR-SSCP) and heteroduplex analysis using two different experimental conditions [8]. The PTEN was amplified in 10 segments (225-310 bp) on $100 \mathrm{ng}$ of genomic DNA [8]. Individual PCR conditions and primers, located in intronic sequences to avoid amplification of the PTEN pseudogene $\Psi P T E N$, were designed from the genomic sequence (Acc. No. AF000726-AF000734). For PCR amplification we used sense (a) 5'-3'/antisense (b) 5'-3' primers for each segment (intron) followed by an indication of the specific annealing temperatures and $\mathrm{Mg}^{2+}$ concentrations (temp/ $\mathrm{Mg}^{2+}$ $\mathrm{mmol} / \mathrm{l}): 1 \mathrm{a} / \mathrm{b}$, cttctgccatctctctcctc/actacggacattttcgcatc, $55 \%$ 2.0; $2 \mathrm{a} / \mathrm{b}$ ccatgtggaagttacctttta*/aataatgttcctgtatacgc*, 55 $\%$. $3 \mathrm{a} / \mathrm{b}$ ggtggctttttgtttgtttg*/ttaatcggtttaggaatacaa*, $55 \% / 1.5 ; 4 \mathrm{a} / \mathrm{b}$ gggggtgataacagtatc/catagtacagtacattcatacc, $55^{\circ} / 1.5 ; \quad 5 \mathrm{a} / \mathrm{b}$ tcttattctgaggttatcttttacc/tccaggaagaggaaaggaaa, $55 \% 1.5 ; 6 \mathrm{a} / \mathrm{b}$ catagcaatttagtgaaataact/gatatggttaagaaaactgttc, $55^{\circ} / 1.5 ; 7 \mathrm{a} / \mathrm{b}$ tgacagtttgacagttaaagg/ggatattctcccaatgaaag, $55^{\circ} / 2.0 ; 8 \mathrm{a} / \mathrm{b}$ cattcttcataccaggaccag*/tcatgttactgctacgtaaac*, 55\% $1.5 ; 9 \mathrm{a} / \mathrm{b}$ ctcagattgccttataatagtc*/cgatttcttgatcacatag*, $\quad 55 \% 1.5 ; \quad 10 \mathrm{a} / \mathrm{b}$ tcatattgtgggttttcattt/tttcatggtgttttatccctc, $55^{\circ} / 2.0$. Only exon 8 was divided into two segments $(8+9)$. Primers also used for sequencing are marked by an asterisk. The PCR conditions were the following: initial denaturation at $95^{\circ} \mathrm{C}$ for $2 \mathrm{~min}, 35$ cycles of denaturation at $94^{\circ} \mathrm{C}, 30 \mathrm{~s}$, annealing $30 \mathrm{~s}$, elongation for $30 \mathrm{~s}$ at $72^{\circ} \mathrm{C}$ and final elongation at $72^{\circ} \mathrm{C}$ for $9 \mathrm{~min}$. 
Table 2. Clinical and physiological characteristics of 224 glucose-tolerant control subjects, classified according to the $P T E N$ genotype, at position IVS $8+32 \mathrm{G} \rightarrow \mathrm{T}$

\begin{tabular}{|c|c|c|c|c|}
\hline & $\mathrm{Wt}$ & Het & Ho & $p$-value \\
\hline Number (men/women) & $94(43 / 51)$ & $105(57 / 48)$ & $25(11 / 14)$ & \\
\hline Age (years) & $53.6(13.2)$ & $52.2(14.3)$ & $45.8(12.9)$ & \\
\hline Systolic blood pressure (mm Hg) & $139(21)$ & $141(19)$ & $138(17)$ & 0.34 \\
\hline Diastolic blood pressure ( $\mathrm{mm} \mathrm{Hg}$ ) & $89(11)$ & $91(12)$ & $90(10)$ & 0.51 \\
\hline HOMA index (fmol/l) & $231(147)$ & $217(116)$ & $180(86)$ & 0.26 \\
\hline $\begin{array}{l}\text { At } 30 \text { min during OGTT } \\
\text { Plasma glucose }(\mathrm{mmol} / \mathrm{l}) \\
\text { Serum insulin }(\mathrm{pmol} / \mathrm{l}) \\
\text { Serum C peptide }(\mathrm{pmol} / \mathrm{l})\end{array}$ & $\begin{array}{c}7.7(1.6) \\
263(108-418) \\
1640(1065-2305)\end{array}$ & $\begin{array}{c}7.9(1.4) \\
272(105-482) \\
1695(1140-2410)\end{array}$ & $\begin{array}{c}7.7(1.3) \\
223(82-376) \\
1434(884-2154)\end{array}$ & $\begin{array}{l}0.15 \\
0.70 \\
0.57\end{array}$ \\
\hline
\end{tabular}

Data represent means (SD) or means (10-90 per centile range) for log-transformed data (serum insulin and serum $C$ peptide). $\mathrm{Wt}$, wildtype; He, heterozygote; Ho, homozygote. A generalized linear model was used to compare the wildtype, heterozygous and homozygous carriers. In the analysis age, BMI

The SSCP variants were sequenced using Thermo Sequenase (Amersham, Cleveland, Ohio, USA) as described [8]. Mutations occurring within intronic regions are named IVS, followed by the intron number and a plus/minus, indicating the position of either downstream or upstream from the corresponding exon, and the given nucleotide changes. Genotyping of the $\mathrm{G} \rightarrow \mathrm{T}$ variant in position IVS $8+32$ was done by PCR amplification of segment 8 using primers $8 \mathrm{a}, 8 \mathrm{~b}$ and restriction fragment length polymorphism (RFLP) using $H p h \mathrm{I}$ restriction enzyme. The fragments were separated on a $3 \%$ agarose gel and visualised by staining with ethidium bromide.

Biochemical assays. $\mathrm{HbA}_{1 \mathrm{c}}$, plasma glucose, serum insulin, and serum $C$ peptide were analysed as described previously [7] and the HOMA insulin resistance index was calculated as the product of fasting plasma glucose and fasting serum insulin, leaving out the 22.5 constant.

Statistical analysis. Chi-squared and Fishers exact test as implemented in AssoTest ver. 04 a (Steno Diabetes Center, Dept. 521, Copenhagen, Denmark) was applied to test for any significant differences in allele frequencies. Normal distribution of the residuals were visually verified and data were logarithmically transformed if necessary. Serum insulin and serum $C$ peptide concentrations were logarithmically transformed at all times. Statistical Package of Social Science (SPSS) for Windows, version 9.0 was used for analysis applying a generalized linear model. The analyses included age, BMI and sex as covariates. For the analysis of $30 \mathrm{~min}, 60 \mathrm{~min}$, and $120 \mathrm{~min}$ concentrations of circulating insulin and $\mathrm{C}$ peptide, the corresponding fasting concentrations were also included as covariate in the model to account for differences in basal concentrations among subjects. A $p$-value of less than 0.05 was considered statistically significant. Data in text and table are given as means (SD). and gender were included as covariates. For the analysis of $30 \mathrm{~min}, 60 \mathrm{~min}$ and $120 \mathrm{~min}$ values of circulating insulin and $\mathrm{C}$ peptide, the corresponding fasting concentrations (as a measure of insulin sensitivity) were added as covariates

\section{Results}

By applying PCR-SSCP-heteroduplex analysis and direct sequencing of the gene encoding the PTEN protein in patients with insulin-resistant Type II diabetes, we identified no coding region variants, but four intronic polymorphisms: IVS1-96 $\mathrm{A} \rightarrow \mathrm{G}$ (allelic frequency $0.22,95 \%$ CI: $0.12-0.32), \mathrm{IVS} 3+99 \mathrm{C} \rightarrow \mathrm{T}$ (0.01, CI: $\quad 0-0.03), \quad$ IVS7-3 TT $\rightarrow$ T $\quad(0.10, \quad$ CI: $0.03-0.18)$ and IVS $8+32 \mathrm{G} \rightarrow \mathrm{T}(0.35$, CI: $0.23-0.47)$. The IVS7-3 TT $\rightarrow \mathrm{T}$ is a deletion of the last $\mathrm{T}$ in a stretch of fifteen T's in the 3'-end of intron 7 and does not predict any changes in the splice acceptor consensus sequence. The IVS $8+32 \mathrm{G} \rightarrow \mathrm{T}$ variant was used as a bi-allelic marker for the PTEN locus as a potential diabetes-associated chromosomal locus in an association study comprising 379 patients with Type II diabetes and 224 normal glucose-tolerant control subjects, matched for age, BMI and gender. The examined IVS $8+32 \mathrm{G} \rightarrow \mathrm{T}$ variant was in Hardy-Weinberg equilibrium. The allelic frequency of the IVS $8+32 \mathrm{G} \rightarrow \mathrm{T}$ variant was not different between patients with Type II diabetes (allelic frequency 0.35 , CI: $0.30-0.40$ ) and the control subjects (allelic frequency 0.35 , CI: $0.28-0.42$ ). The IVS $8+32 \mathrm{G} \rightarrow \mathrm{T}$ variant did not have any impact on insulin resistance (HOMA index) and it did not interact with obesity (BMI) in either the Type II diabetic subjects or the glucose-tolerant control subjects when a $P T E N^{*} \mathrm{BMI}$ interaction term was included in the regression analy- 
sis (data not shown). Furthermore, the IVS +32 $\mathrm{G} \rightarrow \mathrm{T}$ polymorphism did not have any significant effect on systolic or diastolic blood pressure and it was not associated with changes in plasma glucose, serum insulin and $\mathrm{C}$ peptide concentrations in the fasting state or during a WHO standardized oral glucose tolerance test (OGTT) in the 224 control subjects (Table 2).

\section{Discussion}

This study on PTEN as a candidate gene for the common late-onset Type II diabetes in Caucasians is based on knowledge of the pathophysiology of insulin resistance and Type II diabetes and it is a continuation of our genetic dissection of the metabolic pathways of insulin signalling in search for gene variants that associate with Type II diabetes and quantitative metabolic traits [9]. Genome-wide linkage studies in the Mexican American population have identified a susceptibility locus for Type II diabetes on chromosome $10 \mathrm{q}$ [10]. This region on the chromosome $10 \mathrm{q}$ harbours positional candidate genes for Type II diabetes and occasionally such a positional candidate gene also qualifies as a pathophysiological candidate gene for Type II diabetes and insulin resistance. As we have not done a genome-wide linkage analysis we do not have linkage to chromosome $10 \mathrm{q}$ from Danish subjects with Type II diabetes. With its key position in the insulin signalling pathway [2] and the fact that it maps to chromosome $10 \mathrm{q}$ [3], the PTEN also makes an excellent candidate gene for Type II diabetes susceptibility in the Danish Caucasian population. Another positional candidate gene (PPP1R5) from chromosome $10 \mathrm{q}$ did not contain mutations associated with Type II diabetes in the Danish Caucasians [9].

In this study we failed to detect genetic variants that would predict changes in the PTEN protein either in the form of amino acid substitutions or alternative splicing. Furthermore, we found no evidence for an association of the PTEN locus with Type II diabetes or relevant quantitative metabolic traits (insulin-resistant phenotypes) when the IVS $8+32 \mathrm{G} \rightarrow \mathrm{T}$ variant was applied as a bi-allelic marker. We therefore conclude that variability in the coding region of the PTEN is not likely to be a common cause of
Type II diabetes and insulin-resistant phenotypes in Danish Caucasian subjects.

Acknowledgements. This study was supported by grants from the Danish Research Academy, the Danish Medical Research Council (Cellular and Growth Regeneration), the Velux Foundation, the Danish Diabetes Association and EU (BMH4-CT98-3084). The authors thank A. Forman, H. Fjordvang, L. Aabo, S. Urioste, and B. Mottlau, for their dedicated and careful technical assistance and G. Lademann for her secretarial support.

\section{References}

1. Beck-Nielsen H, Groop LC (1994) Metabolic and genetic characterization of prediabetic states - sequence of events leading to non-insulin-dependent diabetes-mellitus. J Clin Invest 94: 1714-1721

2. Taha C, Klip A (1999) The insulin signaling pathway. J Memb Biol 169: 1-12

3. Steck PA, Pershouse MA, Jasser SA et al. (1997) Identification of a candidate tumor-suppressor gene, mmac1, at chromosome 10q23.3 that is mutated in multiple advanced cancers. Nat Genet 15: 356-362

4. Stambolic V, Suzuki A, Delapompa JL et al. (1998) Negative regulation of pkb/akt-dependent cell-survival by the tumor-suppressor pten. Cell 95: 29-39

5. Kim Y-B, Peroni OD, Franke TF, Kahn BB (2000) Divergent regulation of Akt1 and Akt 2 isoforms in insulin target tissues of obese Zucker rats. Diabetes 49: 847-856

6. Mckay RA, Butler M, Popoff IJ et al. (2000) Specific inhibition of PTEN expression with antisense oligonucleotide normalizes plasma glucose in $\mathrm{db} / \mathrm{db}$ mice. Diabetes [Suppl 1] A51: 207-OR

7. Almind K, Bjorbaek C, Vestergaard H et al. (1993) Aminoacid polymorphisms of insulin-receptor substrate-1 in noninsulin-dependent diabetes-mellitus. Lancet 342: 828-832

8. Hansen L, Echwald SM, Hansen Tet al. (1997) Amino-acid polymorphisms in the ATP-regulatable inward rectifier KIR6.2 and their relationships to glucose-induced and tolbutamide-induced insulin-secretion, the insulin sensitivity index, and NIDDM. Diabetes 46: 508-512

9. Hansen L, Fjordvang H, Rasmussen SK et al. (1999) Mutational analysis of the coding regions of the genes encoding protein kinase B-alpha and -beta, phosphoinositide- dependent protein kinase-1, phosphatase targeting to glycogen, protein phosphatase inhibitor-1, and glycogenin Lessons from a search for genetic variability of the insulinstimulated glycogen synthesis pathway of skeletal muscle in NIDDM patients. Diabetes 48: 403-407

10. Duggirala R, Blangero J, Almasy L et al. (1999) Linkage of Type II diabetes mellitus and of age at onset to a genetic location on chromosome $10 \mathrm{q}$ in Mexican Americans. Am J Hum Genet 64: 1127-1140 